\title{
Variations of the Wake Height over the Bolund Escarpment Measured by a Scanning Lidar
}

\author{
Julia Lange ${ }^{1} \cdot$ Jakob Mann$^{1} \cdot$ Nikolas Angelou $^{1}$. \\ Jacob Berg' ${ }^{1}$ • Mikael Sjöholm ${ }^{1}$. Torben Mikkelsen ${ }^{1}$
}

Received: 20 February 2015 / Accepted: 27 October 2015 / Published online: 7 November 2015

(C) The Author(s) 2015. This article is published with open access at Springerlink.com

\begin{abstract}
The wake zone behind the escarpment of the Bolund peninsula in the Roskilde Fjord, Denmark, has been investigated with the help of a continuous-wave Doppler lidar. The instrument measures the line-of-sight wind speed 390 times per second in highly resolved 7$\mathrm{m}$ tall profiles by rapidly changing the focus distance and beam direction. The profiles reveal the detailed and rapidly changing structure of the wake induced by the Bolund escarpment. The wake grows with distance from the escarpment, with the wake height depending strongly on the wind direction, such that the minimum height appears when the flow is perpendicular to the escarpment. The wake increases by 10-70\% when the wind direction deviates $\pm 15^{\circ}$ from perpendicular depending on the distance to the edge and to a lesser degree on the method by which the wake height is determined. This finding is supported by a comparison with in situ measurements acquired on the Bolund peninsula.
\end{abstract}

Keywords Bolund · Complex flow · Wake height · WindScanner

\section{Introduction}

Complex terrain creates complex atmospheric flow. Complex terrain, which is characterized by a high variance in the surface characteristics such as roughness and elevation, causes the growth of local turbulent structures that are hard to predict. Such turbulent structures are far from fully understood and are typically found in wake regions in the immediate rear of solid bodies. Over steep hills these wake areas consist of complex turbulent structures and time varying processes that so far defy reliable prediction through numerical modelling.

The knowledge of these turbulent structures in the wake region is important for assessment of the impact of wind and turbulence on buildings, constructions and especially wind turbines. For wind turbines in particular the wake height on top of escarpments is important.

Julia Lange

jull@dtu.dk

1 DTU Wind Energy, Technical University of Denmark, Ris $\emptyset$ Campus, 4000 Roskilde, Denmark 

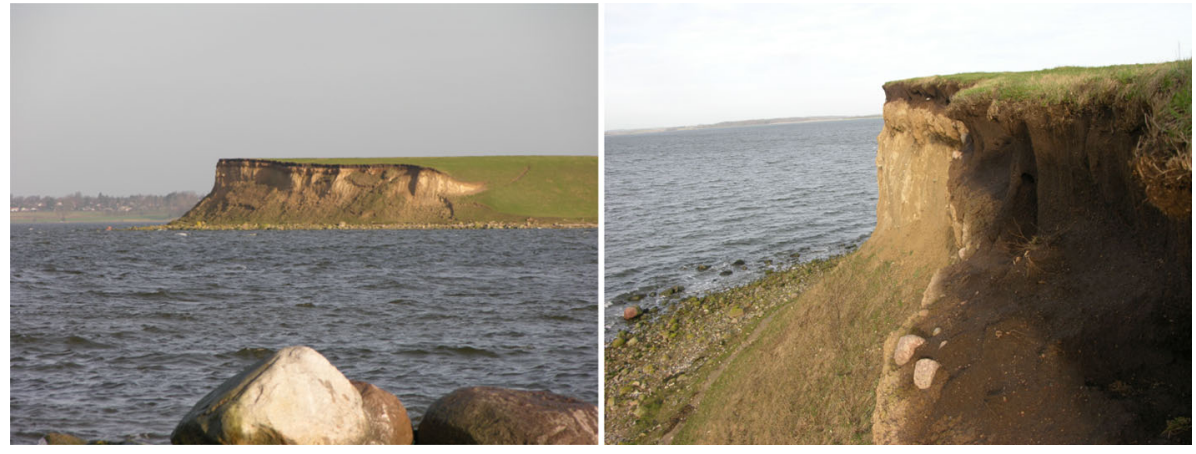

Fig. 1 Left Photo of Bolund, taken south of the peninsula. Right Photo of the Bolund escarpment edge

To reduce stress on the turbines, it is required to construct them in a way that the lower part of the rotor is almost always above the turbulence caused by the escarpment. Because atmospheric experiments are often time consuming and costly, engineers and atmospheric scientists, engaged in modelling and assessing wind loads on buildings and siting of wind turbines in complex terrain, often resort to numerical models of varying fidelity to achieve insight into complex flow fields. The validation and eventually the improvement of those models often relies heavily on comparisons with suitable high-quality wind and turbulence field measurements.

During the last four decades various experimental studies have been performed, with the aim of characterizing complex flow over hills. Studies over hills with gentle slopes have been performed by Sacré (1979), Baskaran et al. (1987) and Walmsley and Taylor (1996) in which the growth of the internal boundary layer and the influences of roughness changes are described. Jensen and Peterson (1978) investigated roughness changes along the Ris $\varnothing$ peninsula. The flow over several escarpments, including vertical profiles and turbulence structures in New Zealand have been studied by Bowen (1979). A more complex field experiment, the Hjardemål experiment, was analyzed by Emeis et al. (1995), where mean flow profiles, turbulent power spectra and momentum flux were investigated.

One of the best known hill experiments, is the Askervein Hill experiment described by Taylor and Teunissen (1985). The results of the Askervein Hill experiment have been used for many comparison studies with numerical models (Jackson and Hunt 1975; Hunt et al. 1988; Castro et al. 2003; Silva Lopes et al. 2007; Chow and Street 2009) and wind-tunnel studies (Teunissen et al. 1987).

This more recent field experiment builds on previous studies and examines the flow over the Bolund peninsula. Bolund is an isolated flat-topped hill with steep sides in the Roskilde Fjord, Denmark, that is connected to land at low tide with an isthmus on the east side. The hill extends $150 \mathrm{~m}$ in the west-east direction, is $75 \mathrm{~m}$ wide on the north-south axis and is about 12 $\mathrm{m}$ high. A contour plot is available in Berg et al. (2011). The shape of the peninsula includes a west facing, mostly vertical escarpment (Fig. 1) that is accountable for a recirculation zone in front of the cliff and a detachment of the flow above the edge for westerly winds. The flow reattaches on the long, flat hill top, before the terrain slopes down towards the east (Yeow et al. 2013). These flow patterns make the prediction and modelling of the flow around Bolund challenging, but also well defined through well-known boundary conditions and especially through the 7-km long upstream water fetch on the west site. 
DTU Wind Energy performed an atmospheric experiment at the Bolund peninsula during winter 2007-2008 in order to make a test case for flow modelling in complex terrain (Bechmann et al. 2011; Berg et al. 2011). The two-month long intensive measurement campaign produced a unique dataset of sonic and cup anemometer measurements at various heights for selected locations on the Bolund peninsula. Vertical lidar wind profiles complement the dataset (Bechmann et al. 2009, 2011; Berg et al. 2011). Today the dataset of the Bolund experiment serves as a baseline reference for various studies with respect to numerical and physical modelling.

Initially the Bolund dataset was used for a blind comparison of different microscale flow models, including simple linear models such as WAsP, non-linear models such as Reynoldsaveraged Navier-Stokes (RANS) models and large-eddy simulation (LES), as well as physical models using wind-tunnel and water-channel facilities (Bechmann et al. 2011). Every participant was given the same information about topography, roughness and inflow conditions. There was significant scatter for both wind speed and turbulence levels among the different models, indicating that numerical models still have to develop in order to successfully model flow over real complex terrain.

An additional RANS solver verification was carried out by Prospathopoulos et al. (2012). The Bolund experimental dataset was used to verify the quality of a steady state RANS solver with a two-equation turbulence model. Difficulties with the modelling of the sharp escarpment lead to deviations between the predictions and the observed values downstream of the cliff. The deviation decreased with height. It was also stated that the predictions of the main flow are reliable, but that it was not possible to reproduce the turbulent behaviour of the flow with the applied method. The usage of a more advanced method, like LES, to improve the results for such complex terrain was suggested.

Furthermore Diebold et al. (2013) reproduced the flow around Bolund with the immersed boundary condition method using an LES model. Although close agreement was found with the field measurements, problems occurred in modelling locations close to the escarpment and close to the ground. The increased deviations from the field measurements are explained by insufficient information about the surface roughnesses and by a too coarse model grid.

The Bolund experiment was not only used to verify numerical models, it has also been used to prove the applicability of wind tunnels for atmospheric flow modelling. Yeow et al. (2013) conducted a wind-tunnel study to reproduce the wind flow around Bolund, where they focused on the main flow patterns that occur with the flow over a hill.

Yeow et al. (2013) reproduced the Bolund experiment on a scale of 1:115 in a neutral boundary-layer wind tunnel for two different Reynolds numbers. Particle image velocimetry (PIV) and a three-component hot-wire probe were used to obtain results along the $270^{\circ}$ axis. The wind-tunnel measurements are in close agreement with the Bolund field measurements. However, vertical scans in the wind tunnel showed that the Bolund escarpment represents a critical point in the flow, indicating an over-prediction of the speed-up downstream of the escarpment at $2 \mathrm{~m}$ height. This deviation is not present at $5 \mathrm{~m}$ above the terrain. One possible explanation for the deviation is that Yeow et al. (2013) are not able to reproduce the inflow profile from the Bolund experiment. A second potential cause for the discrepancies is given by the fact that the ratio between the atmospheric boundary-layer height and the height of the peninsula in the wind tunnel is smaller than at full scale. These circumstances subsequently influence the flow perturbation caused by the peninsula and the resulting flow pattern evolution.

A similar experiment is carried out by Conan (2012), with a model scale of 1/500. Although he is able to reproduce the inlet conditions closer to the real inflow than Yeow et al. (2013), his results of the flow evolution on top of Bolund show similar deviations from the real scale. 
Recently, Rowcroft et al. (2014) conducted extensive wind-tunnel tests on a forwardfacing step with varying wind direction. They found a small increase of the reattachment length with increasing deviation from perpendicular flow. Unfortunately, they did not report on the wake height induced by the forward-facing step, making direct comparison with this study difficult.

Many of the mentioned studies state that their comparisons would improve with more detailed information about the flow. Especially the detachment and the wake area behind the edge of the escarpment have been the most problematic regions to model. To obtain a more comprehensive understanding of the flow pattern over the Bolund peninsula, especially close to the surface, a second field campaign deploying a scanning wind lidar was conducted in October 2011 by DTU Wind Energy. A preliminary investigation of this measurement campaign was carried out by Mann et al. (2014).

In the following section the set-up and procedure of the field campaign is explained, including a description of the scanning Doppler lidar. The lidar measurements are presented in the results section and followed by an investigation of the measured line-of-sight wind speeds. Subsequently, an analysis of the wake-height growth over Bolund show a large dependence on the upstream approaching wind direction. A conclusion summarizes the study and gives suggestions for future field measurement campaigns.

\section{The Experiment}

To gain insight into the recirculation zone downstream of the escarpment a complementary field experiment on the Bolund peninsula was conducted. In October 2011 a laser anemometer, in the following called WindScanner, was placed on the peninsula $20 \mathrm{~m}$ inland from the westward facing escarpment. The WindScanner, aligned on the $270^{\circ}$ axis, was operated during westerly wind conditions to scan the area downstream of the Bolund edge. This experimental set-up stayed fixed during the whole experiment. The atmospheric inflow was measured in seven, 7-m high, vertical profiles with distances of 8, 10.75, 14, 16, 18, 20, 31 $\mathrm{m}$ from the scanning lidar as shown in Fig. 2. Figure 2 shows that the first six profiles are located above the peninsula, while the seventh profile is measured upstream, above the water. In addition to the seven vertical profiles a horizontal arc extending $\pm 60^{\circ}$ was scanned 120 $\mathrm{m}$ away from the instrument, at a height $13 \mathrm{~m}$ above the fjord in front of the peninsula (not shown in Fig. 2). Consecutive scans of all eight profiles is defined as one full-scan cycle. Each individual vertical profile consists of approximately 300 single vertical scans, while each vertical scan is constructed from measurements at 40 different heights distributed over the 7-m tall profiles. The eighth profile consists of 60 horizontal scans, while each individual horizontal scan comprises of 390 measurement points along the arc. While westerly wind directions prevailed, lidar measurements were recorded continuously during an almost 24-h long measurement period.

The line-of-sight wind speeds of the eighth profile were used to determine the undisturbed inflow wind speed and wind direction.

Due to the small distances involved in the experiment a short-range WindScanner was used, an instrument developed in the Wind Energy department of the Danish Technical University in collaboration with the lidar manufacturer ZephIR, UK. The lidar is a continuous-wave, coherent Doppler lidar first described in Karlsson et al. (2000). Its two main components are a modified directional sensing version of a commercial ZephIR Z150 wind lidar (Kindler et al. 2007; Smith et al. 2006) and a fast-scanning scanner head (Mikkelsen et al. 2011). 
Fig. 2 The position and height of the seven vertical profiles scanned by the lidar relative to the Bolund escarpment. The position of the WindScanner itself is indicated by the circle. Not shown is the horizontal arc scan, profile 8 , which is located $120 \mathrm{~m}$ from the instrument at a height of $13 \mathrm{~m}$ above the water

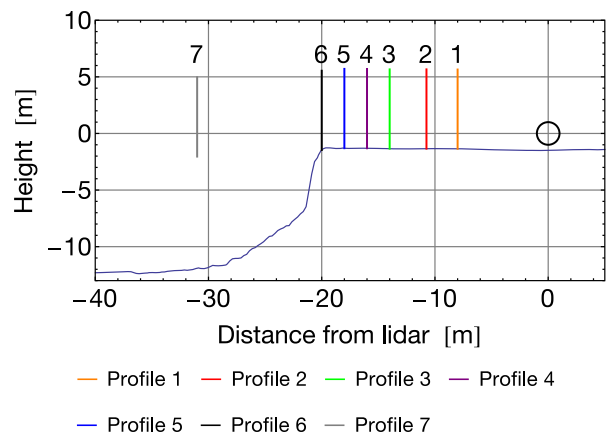

The scanner head consists of two independently controlled top-mounted rotating prisms, each with a $30^{\circ}$ deflection angle that steers the lidar's line-of-sight within a scanning cone with a full opening angle of $120^{\circ}$. The design of the focusing mechanism allows a minimum focusing distance of approximately $8 \mathrm{~m}$. The instrument has been calibrated in order to achieve a pointing accuracy of $0.1^{\circ}$ during scanning. The design of the control system of the scanner head helps provide feedback of the actual position of each of the prisms, which is used to determine the direction of the line-of-sight of the short-range WindScanner. Uncertainties in the position of the measurements will originate mainly from the synchronization of the one radial wind-speed measurement with the corresponding line-of-sight direction defined by the data acquired from the scanner. The synchronization of these two has an uncertainty of $\pm 1.7 \mathrm{~ms}$. Therefore a radial wind speed may be displaced by $(1.7 \mathrm{~ms} \times 7 \mathrm{~m}) /(0.1 \mathrm{~s})=0.119 \mathrm{~m}$ when measuring a 7-m tall profile during $0.1 \mathrm{~s}$. It is confirmed by investigating the position of the wake top during consecutive up and down sweeps that the estimate of the height uncertainty due to synchronization uncertainty is indeed conservative. A more detailed description of the WindScanner measurement technique is found in Sjöholm et al. (2014).

The probe length is defined by the width of the line-of-sight intensity profile of the focused laser-light energy around the focus point, which peaks around the lidar's adjustable focus point. To a good approximation, the line-of-sight intensity profile of a continuous wave lidar, follows a Lorentzian distribution weighting function (Sonnenschein and Horrigan 1971).

The theoretically expected probe lengths have been calculated based on the properties of the optical components of the instrument and have also been experimentally evaluated using hard target return. The probe lengths are represented in Fig. 3, in which highlighted areas correspond to the focus distances used in each of the seven vertical profiles. As far as it concerns the focus distance, the estimated uncertainty will result in an error of determining the point of focus, which will increase along with the distance. For example, at the first profile this is $0.007 \mathrm{~m}$ and at profile 7 it is $0.12 \mathrm{~m}$. The produced laser Doppler spectra contain information about the average wind speed projected to the line-of-sight of the instrument over the probe length (Angelou et al. 2012).

During this experimental set-up 500 laser Doppler spectra were averaged in real time resulting in an effective data-streaming rate of approximately 390 line-of-sight wind-speed samples per second, which corresponds to 40 height measurements per sweep and to approximately 300 vertical profile measurements per profile location. Prior to the post processing of the spectra they are averaged to reduce the noise. More information about the data filtering and processing is described in Angelou et al. (2012). The resulting spectra offer the possibility of measuring radial wind speeds between $0.3 \mathrm{~m} \mathrm{~s}^{-1}$ and $18 \mathrm{~m} \mathrm{~s}^{-1}$ with a Doppler spectral speed resolution of $0.15 \mathrm{~m} \mathrm{~s}^{-1}$. Furthermore the opto-electronic design of the instrument, 
Fig. 3 The probe length of the short-range WindScanner measurements as a function of focus distance. The highlighted areas correspond to the vertical planes scanned during this experiment. Not shown on the figure is profile 8 , which has a focus distance of $120 \mathrm{~m}$ and a probe length of $1.8 \mathrm{~m}$
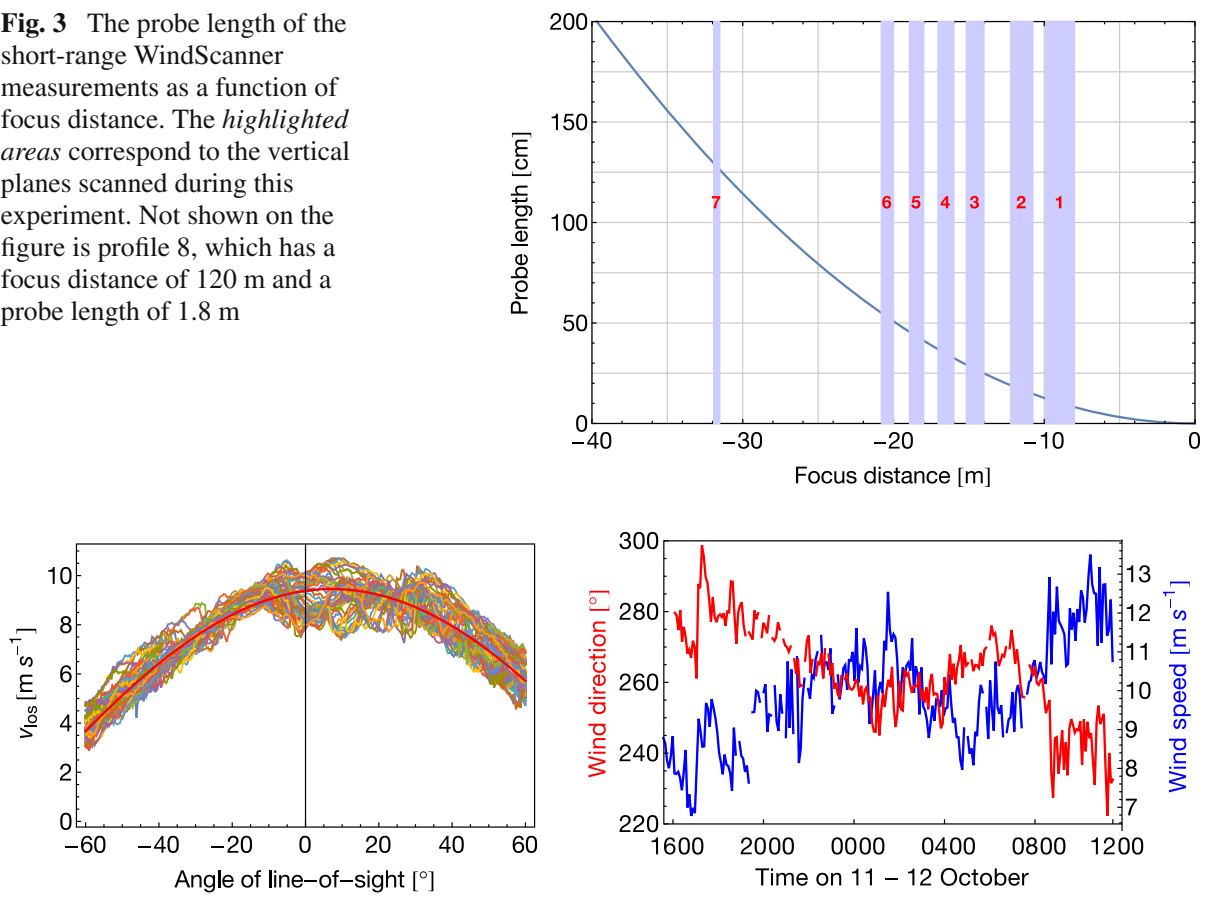

Fig. 4 Left Angle of the wind vector of each measurement relative to the instrument coordinates for one scan cycle of profile 8 . The sinusoidal fit is displayed by the red solid line. Right Development of the undisturbed inflow wind speed and direction over the whole measurement period calculated from profile 8

which includes an optical acoustic modulator, allows for the distinction of the sign of the wind-speed component, not only the absolute value.

The measurement of the line-of-sight wind speed is limited by close to ground and close zero speed measurements (Abari et al. 2015). Due to the lidar's lower wind-speed detection limit $\left(0.3 \mathrm{~m} \mathrm{~s}^{-1}\right), 14$ scan cycles (equal to $70 \mathrm{~min}$ of measurement time) that had more than 1000 consecutive below-limit measurements were filtered out.

The upstream scan of the horizontal plane (profile 8, $120 \mathrm{~m}$ away from the instrument) was used to determine the undisturbed inflow. A RANS simulation (not shown here) shows that the wind direction changes by less than 1/10 degree and that the wind speed reduces by less than $3 \%$ within the upstream distance of $100 \mathrm{~m}$. The measurements of the horizontal profile were used to calculate the angle of the horizontal wind vector of each measurement relative to the instrument's westerly orientation coordinates. A sinusoidal fit was applied to the calculated angle to solve for two unknown parameters, wind speed and wind direction (Fig. 4). The wind direction ranged from $220^{\circ}$ to $300^{\circ}$ and the wind speed increased from 7 to $13 \mathrm{~m} \mathrm{~s}^{-1}$ throughout the measurement period. The average wind speed was $9.3 \mathrm{~m} \mathrm{~s}^{-1}$.

\section{Results}

Figure 5 shows the line-of-sight wind speed over a 30 -s period at profile 2. Fluctuations in positive and negative line-of-sight wind speeds close to the ground and increasing wind speeds with height visualize the dynamics of the unsteady atmospheric flow. 


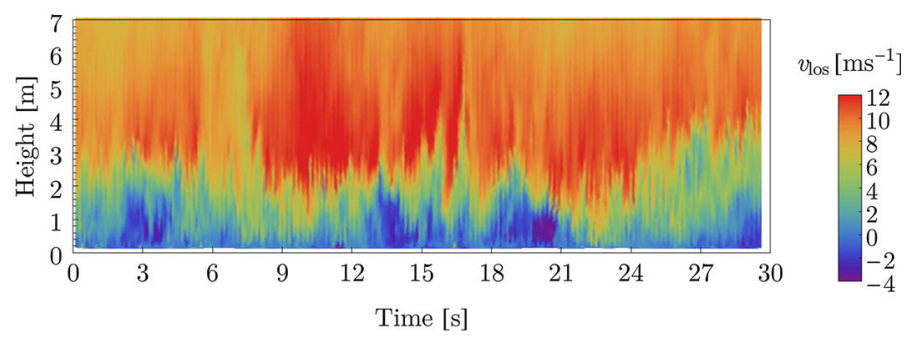

Fig. 5 The line-of-sight wind-speed scan at profile 2, $10.75 \mathrm{~m}$ from the WindScanner over 30 s. 296 consecutive vertical profiles are plotted
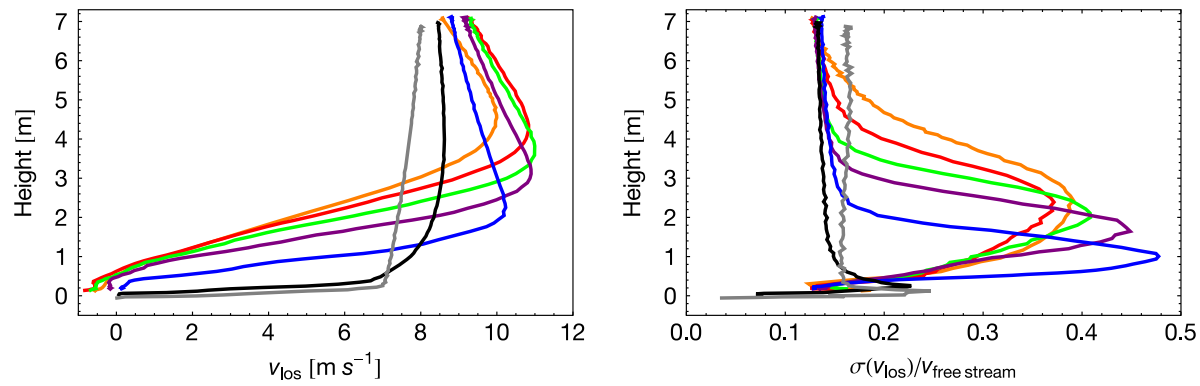

- Profile 1 - Profile 2 - Profile 3 - Profile 4 - Profile 5 - Profile 6 - Profile 7

Fig. 6 Left Time-averaged wind-speed profiles with an inflow wind direction of $270^{\circ} \pm 5^{\circ}$ of all seven vertical profiles. Some profiles show reversed mean flow close to the ground. Right Corresponding profiles of the normalized standard deviation (turbulence intensity) of the line-of-sight wind speed

The time average of the line-of-sight wind speed (approximately $4.5 \mathrm{~h}$ ) at wind directions $270^{\circ} \pm 5^{\circ}$ for each profile leads to the vertical profiles shown in the left panel of Fig. 6. Negative mean line-of-sight wind speeds indicate reversed mean winds close to the ground for profiles 1-4. Already at the position of the escarpment (profile 6) we see a velocity deficit in the lowest 1-2 m (Fig. 6, left) and enhanced turbulence in the lowest $1 \mathrm{~m}$ (Fig. 6, right). We hypothesize that this is created by the stony beach and the rough slope of the escarpment. Profile 6 may also be influenced by moving grass on the edge and therefore the data may be erroneous. The normalized standard deviation of the line-of-sight wind speed (normalized by the freestream wind speed at 7-m height of every profile location) in the right panel of Fig. 6 , reaches its maximum at heights between 1 and $2 \mathrm{~m}$, indicating a high degree of variation. Turbulence intensities show values up to $50 \%$ at these heights. The turbulence profile of profile 7 (located $11 \mathrm{~m}$ upstream of the escarpment) differs from the other six profiles at the upper heights. A different measurement height of 12-19 $\mathrm{m}$ above ground and a different air mass below alters the shape of profile 7. The 1-h mean profile of the standard deviation of the line-of-sight velocity in (Mann et al. 2014, Fig. 6) shows that the deviation of profile 7 can be smaller.

Both figures (Fig. 6, left, right) show a turbulent layer that grows with the distance from the edge.

\subsection{Wake Height-Wind Direction Dependence}

The characteristic of the escarpment-induced wake height is further investigated by identifying the boundary between the turbulent wake layer and the freestream flow above. Due to the 

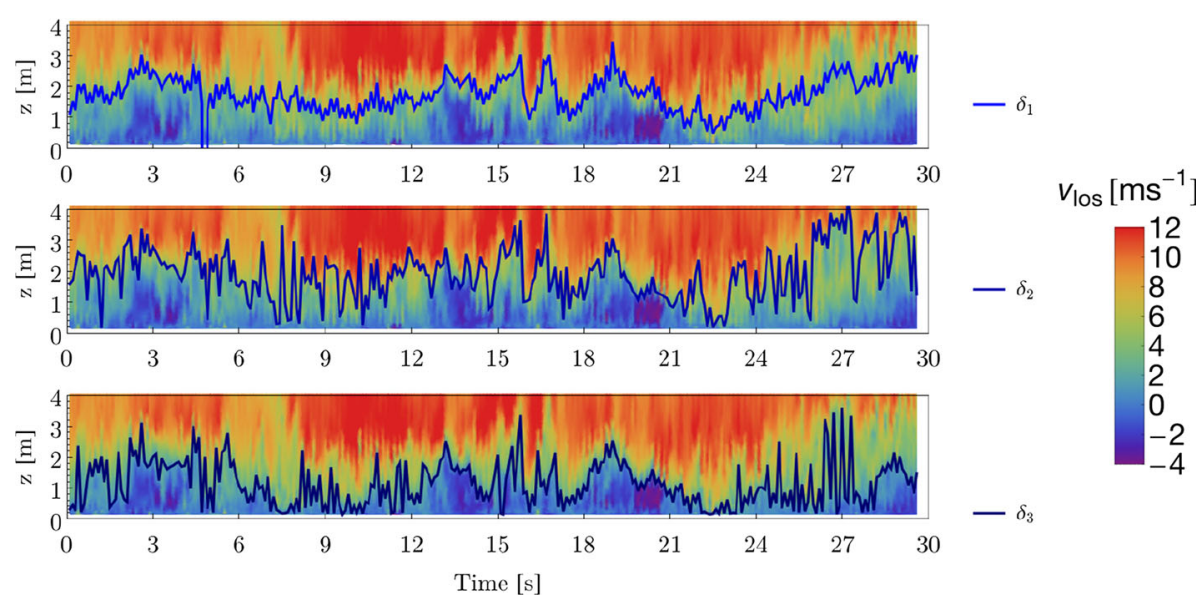

Fig. 7 The line-of-sight projected wind speed of profile 3,12 m away from the WindScanner lasting for $30 \mathrm{~s}$ with the defined wake heights using three different methods

high measurement-sampling rate a precise determination of the interface between the two distinctly different layers is possible. We determine the wake height $\delta$ using three different methods.

1. The first approach determines the displacement thickness, $\delta_{1}$, that is defined as the distance that the boundary layer is displaced to compensate for the reduction in flow rate on account of the wake formation, where $u(z)$ is the line-of-sight wind speed at height $z, z_{\text {top }}$ is the top of the profile, and $u_{0}$ is the freestream velocity (Hinze 1975, pp. 593-597)

$$
\delta_{1}=\int_{0}^{z_{\text {top }}}\left(1-\frac{u(z)}{u_{0}}\right) \mathrm{d} z .
$$

2. The second approach identifies the height of the maximum, arg max, gradient of the line-of-sight wind speed, $\delta_{2}$, of each vertical scan (Emeis et al. 2008, Sect. 2.2.2)

$$
\delta_{2}=\arg \max _{z}\left[\frac{\mathrm{d} u(z)}{\mathrm{d} z}\right] .
$$

3. The third approach identifies the height at which the average between the integral of the two atmospheric layers is the greatest, $\delta_{3}$, which resembles Davis et al. (2000) and Emeis et al. (2008, Sect. 2.2.3),

$$
\delta_{3}=\arg \max _{z}\left[\frac{1}{z_{\text {top }}-z} \int_{z}^{z_{\text {top }}} u(z) \mathrm{d} z-\frac{1}{z} \int_{0}^{z} u(z) \mathrm{d} z\right] .
$$

The results of the wake-height identifications of all three methods are presented in Fig. 7. All three methods manage to identify a wake height, although the actual height differs between the methods. Method 1 gives the highest value of the wake heights.

The calculated wake height for each profile location can be placed in relation to the undisturbed wind direction and speed. The dependence of the wake height, obtained with method 1, on the wind direction is presented in Fig. 8. With increasing distance from the 
Fig. 8 Dependence of the determined wake height with method 1 on the wind direction. The solid lines depict the average wake height
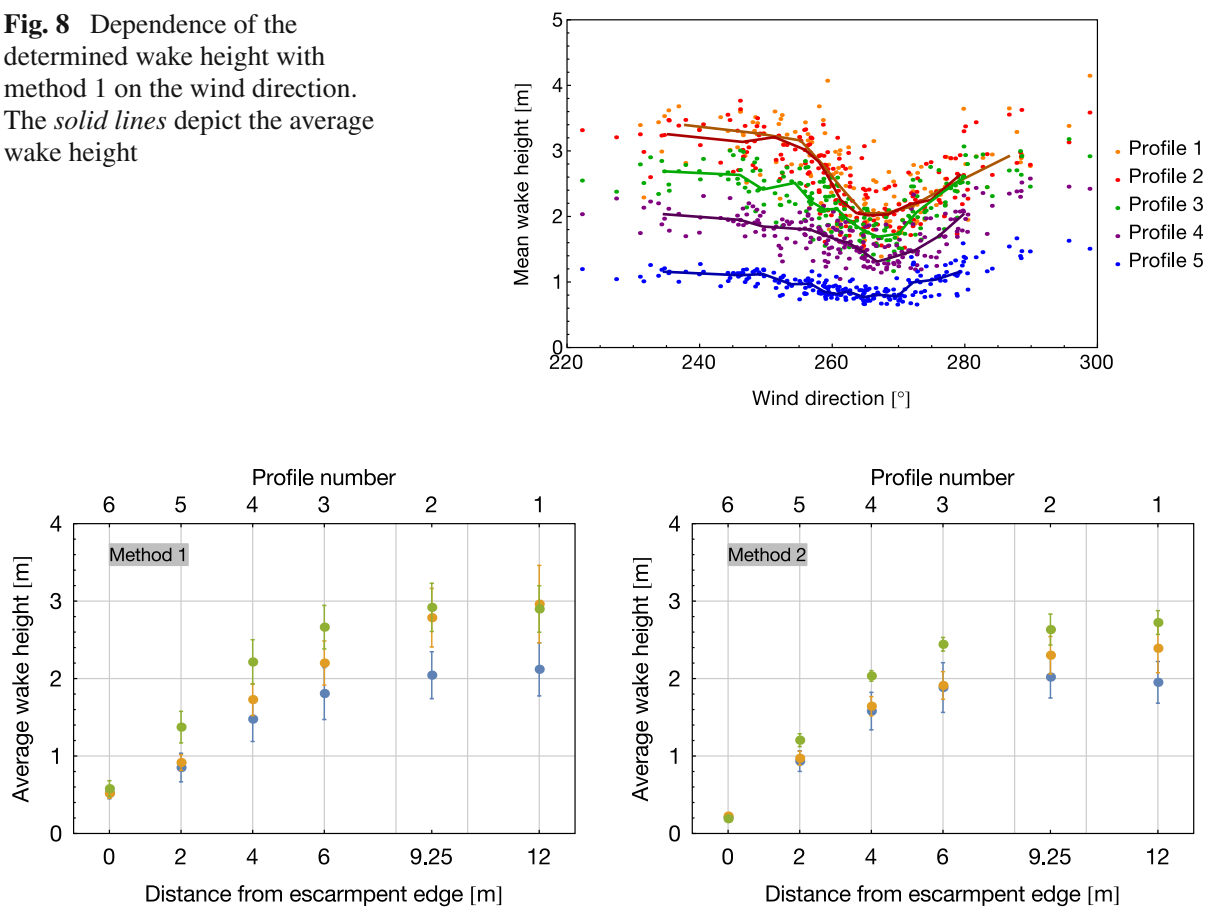

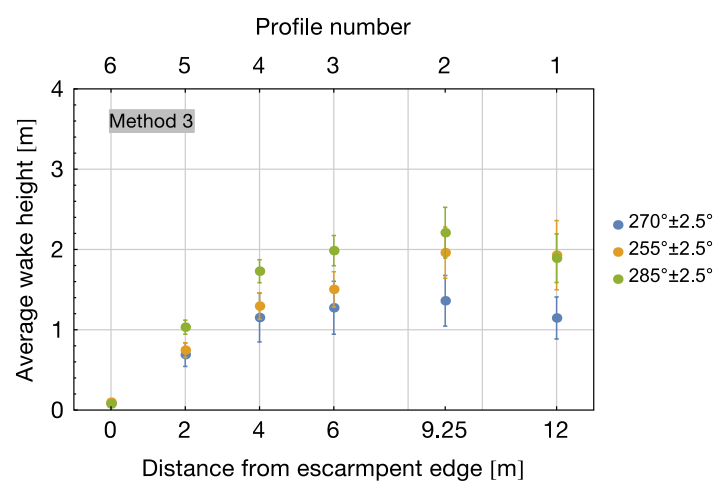

Fig. 9 Averaged wake height for wind-direction bins $270^{\circ} \pm 2.5^{\circ}, 255^{\circ} \pm 2.5^{\circ}$ and $285^{\circ} \pm 2.5^{\circ}$ for six profiles downstream of the edge. The error bars display the corresponding standard deviation of the wake height

escarpment, the wake heights show a stronger dependence on the wind direction. The lowest wake heights of every profile is located at a wind direction of $270^{\circ}$ (Fig. 8). At larger direction deviations the height is near constant. Profile 6 is located over the edge, where no wake develops and is therefore omitted from the plots.

To support the relation between wake height and wind direction we show in Fig. 9 the calculated mean and standard deviation of the wake height, determined with all three methods mentioned above, for three wind-direction bins $\left(270^{\circ} \pm 2.5^{\circ}, 255^{\circ} \pm 2.5^{\circ}\right.$ and $\left.285^{\circ} \pm 2.5^{\circ}\right)$ at every profile. It is seen that the wake height grows with distance to the escarpment, which is also supported by Fig. 6, left panel. Depending on the distance from the escarpment the 


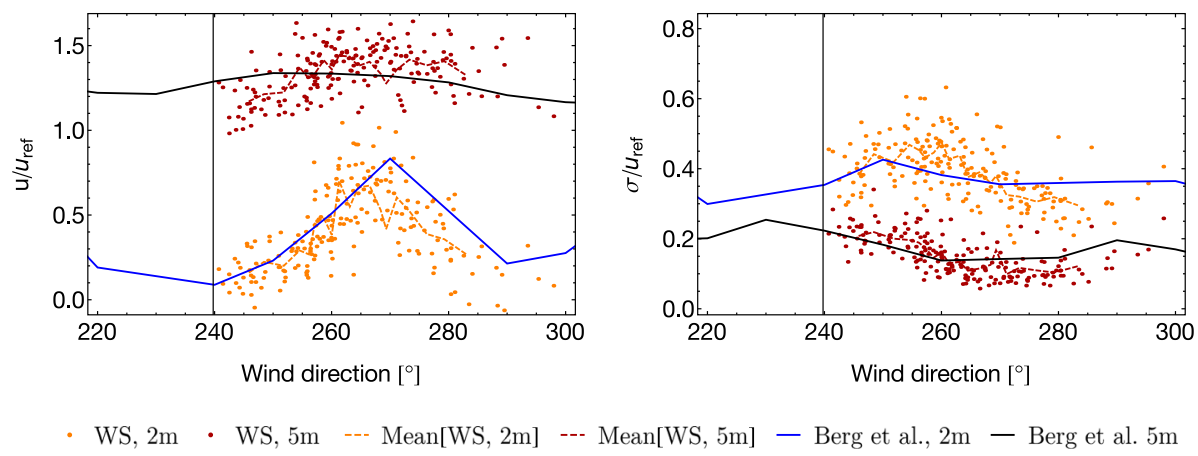

Fig. 10 Left Comparison of the line-of-sight wind speed at profile 2 at 2 and $5 \mathrm{~m}$ with values at M6 from the Bolund experiment (Berg et al. 2011). The reference values $u_{\text {ref }}$ were interpolated logarithmically from $z=13 \mathrm{~m}$ and $z_{0}=0.0006 \mathrm{~m}$ to $5-\mathrm{m}$ height. Right Comparison of the normalized turbulence at profile 2 at 2 and $5 \mathrm{~m}$ with values at M6 from the Bolund experiment (Berg et al. 2011)

wake height increases between 10 and $70 \%$ when the wind direction deviates from west, either to the north or the south $\pm 15^{\circ}$. The standard deviation shows values between $3 \%$ and $20 \%$ of the mean wake-height value. The comparison of the three different methods shows that the direction dependence is not an artefact of the wake-height determination method.

It has also been verified that the wake height is independent of the incoming wind speed (not shown here). The atmospheric stability has not been measured during this experiment, though results from Berg et al. (2011) show that stability changes have only a small effect on wind speeds on Bolund. This implies that the wake height is mainly influenced by the wind direction and the peninsula itself.

\subsection{Comparison of Mast 6 and Profile 2}

To strengthen the finding of the direction dependence, the WindScanner data are compared to the original mast-based Bolund experiment. Profile 2 was measured $10.75 \mathrm{~m}$ away from the WindScanner, which corresponds to the position where mast 6 (M6) was located during the Bolund experiment (Berg et al. 2011), allowing for a comparison of the datasets. In Fig. 9 of Berg et al. (2011), the relative wind speed and the normalized turbulence at M6 are shown relative to the wind direction measured at mast 0 (M0, upstream mast, $100 \mathrm{~m}$ in front of the Bolund peninsula). Berg et al. (2011) used the 5-m high horizontal wind speed at M0 as the reference speed for all cases. For the purpose of this experiment the horizontal speed at M0 at 5-m height was also used as the reference value for the turbulence. These values were calculated for profile 2 . As the reference wind speed the calculated wind speed of the horizontal arc scan at 13- $\mathrm{m}$ height (100 $\mathrm{m}$ in front of the Bolund escarpment, above water) was interpolated logarithmically $\left(z_{0}=0.0006 \mathrm{~m}\right)$ to 5 -m height. Figure 10 , left panel, shows the comparison of the horizontal speed and the line-of-sight wind speed at the location of M6 and profile 2 relative to the wind direction. Both datasets show similar patterns in the same data ranges. A speed-up and an even distribution of the relative speed at all wind directions is seen at $5 \mathrm{~m}$. Both cases show nearly zero mean wind speeds at $2 \mathrm{~m}$, with a clear increase of the normalized wind speed at $270^{\circ}$.

The comparison of the normalized turbulence reveals, in the right panel of Fig. 10, higher turbulence at $2 \mathrm{~m}$ in both datasets. Both M6 (all heights) and profile 2 at 5-m height show, for wind directions near $270^{\circ}$, a clear decrease in the normalized turbulence. A deviation of 
the wind direction from $270^{\circ}$, leads to a turbulence increase. This is in accordance with Figs. 8 and 9 , where the wake height is lowest around $270^{\circ}$ and increases up to $1 \mathrm{~m}$ with a change of wind direction. This agreement supports the relationship between wake height and wind direction.

\section{Conclusion}

The relationship between the wake height and the wind direction revealed in this study is based on the analysis of high frequency atmospheric measurements with a rapidly scanning continuous-wave Doppler lidar. The measurement technique produces highly resolved images of the rapidly changing wake zone of the Bolund peninsula. Seven vertical profiles, each 7-m high, show the development of the escarpment-induced wake. The wake increases in height with distance from the west-facing escarpment and shows highly turbulent structures. The highly resolved measurements allow for a precise determination of the wake height, which was calculated using three different methods. All three methods show a surprisingly sharp increase of the wake height with deviation of the wind direction from $270^{\circ}$. As the wind direction deviates from west by $\pm 15^{\circ}$, the height grows between $10 \%$ and $70 \%$ depending on the distance from the edge with the strongest effect farthest from the edge. This behaviour of the wake height can also be seen in the data of the mast-based Bolund experiment (Berg et al. 2011), where this relation has not been emphasized before.

For future campaigns we suggest a longer measurement campaign, which should improve the statistical significance of the quantitative findings, although we have no reason to expect the main qualitative findings to change. Additionally, stability measurements along side the WindScanner measurements would add an extra dimension to the study of the growth of the wake zone, although we believe that due to the low height of Bolund (12 m) stability effects are small. Also a wind vane upstream would allow more frequent wind-direction measurements and serve as a control for the wind-direction determination from the horizontal plane scan. To extend the experiment the usage of three WindScanners would allow the measurement of all three wind components and lead to a more comprehensive picture of the recirculation zone.

Acknowledgments This work is supported by the Center for Computational Wind Turbine Aerodynamics and Atmospheric Turbulence funded by the Danish Council for Strategic Research, grant number 09-067216. The authors gratefully acknowledge the financial support from the Danish Agency for Science, Technology and Innovation through grant number 2136-08-0022, the windscanner.dk project. Finally the authors are thankful to Neil Davis from DTU Wind Energy for providing valuable language feedback.

Open Access This article is distributed under the terms of the Creative Commons Attribution 4.0 International License (http://creativecommons.org/licenses/by/4.0/), which permits unrestricted use, distribution, and reproduction in any medium, provided you give appropriate credit to the original author(s) and the source, provide a link to the Creative Commons license, and indicate if changes were made.

\section{References}

Abari CF, Pedersen AT, Dellwik E, Mann J (2015) Performance evaluation of an all-fiber image-reject homodyne coherent Doppler wind lidar. Atmos Meas Tech 8(4):3729-3752. doi:10.5194/amtd-8-3729-2015

Angelou N, Mann J, Sjöholm M, Courtney M (2012) Direct measurement of the spectral transfer function of a laser based anemometer. Rev Sci Inst 83(3):33,111 
Baskaran V, Smits A, Joubert P (1987) A turbulent flow over a curved hill. Part 1. Growth of an internal boundary layer. J Fluid Mech 182:47-83

Bechmann A, Berg J, Courtney M, Jørgensen H, Mann J, Sørensen N (2009) The Bolund experiment: overview and background Ris $\varnothing$-R-Report. Tech. Rep., July, Ris $\varnothing-D T U$, National Laboratory for Sustainable Energy, Roskilde

Bechmann A, Sørensen NN, Berg J, Mann J, Réthoré PE (2011) The Bolund experiment, Part II: blind comparison of microscale flow models. Boundary-Layer Meteorol 141(2):245-271. doi:10.1007/ s10546-011-9637-x

Berg J, Mann J, Bechmann A, Courtney M, Jørgensen H (2011) The Bolund experiment, part I: flow over a steep, three-dimensional hill. Boundary-Layer Meteorol 141(2):219-243

Bowen A (1979) Some effects of escarpments on the atmospheric boundary layer. PhD Dissertation, University of Canterbury

Castro FA, Palma JMLM, Lopes AS (2003) Simulation of the Askervein flow. Part 1: Reynolds averaged Navier-Stokes equations ( $k-\epsilon$ turbulence model). Boundary-Layer Meteorol 107(3):501-530

Chow FK, Street RL (2009) Evaluation of turbulence closure models for large-eddy simulation over complex terrain: flow over Askervein Hill. J Appl Meteorol Climatol 48(5):1050-1065

Conan B (2012) Wind resource assessment in complex terrain by wind tunnel modelling. PhD Thesis, Karman Institute/Orléans University

Davis KJ, Gamage N, Hagelberg CR, Kiemle C, Lenschow DH, Sullivan PP (2000) An objective method for deriving atmospheric structure from airborne lidar observations. J Atmos Ocean 17(11):1455-1468. doi:10.1175/1520-0426(2000)0171455:AOMFDA2.0.CO;2

Diebold M, Higgins C, Fang J, Bechmann A, Parlange M (2013) Flow over hills: a large-eddy simulation of the Bolund case. Boundary-Layer Meteorol 148(1):177-194

Emeis S, Frank H, Fiedler F (1995) Modification of air flow over an escarpment. Results from the Hjardemål experiment. Boundary-Layer Meteorol 74(1-2):131-161

Emeis S, Schäfer K, Münkel C (2008) Surface-based remote sensing of the mixing-layer height-a review. Meteorol Z 17(5):621-630. doi:10.1127/0941-2948/2008/0312

Hinze J (1975) Turbulence, 2nd edn. McGraw-Hill Book Co, New York, 790 pp

Hunt J, Leibovich S, Richards K (1988) Turbulent shear flows over low hills. Q J R Meteorol Soc 114:14351470

Jackson P, Hunt J (1975) Turbulent flow over a low hill. Q J R Meteorol Soc 101:929-955

Jensen N, Peterson E (1978) On the escarpment wind profile. Q J R Meteorol Soc 104(441):719-728

Karlsson C, Olsson FA, Letalick D, Harris M (2000) All-fiber multifunction continuous-wave coherent laser radar at $1.55 \mu \mathrm{m}$ for range, speed, vibration, and wind measurements. Appl Opt 39(21):3716-3726

Kindler D, Oldroyd A, MacAskill A, Finch D (2007) An eight month test campaign of the Qinetiq ZephIR system: preliminary results. Meteorol Z 16(5):479-489

Mann J, Angelou N, Sjöholm M, Mikkelsen T, Hansen K, Cavar D, Berg J (2014) Laser scanning of a recirculation zone on the Bolund escarpment. J Phys Conf Ser 555. doi:10.1088/1742-6596/555/1/ 012066

Mikkelsen T, Mann J, Nielsen M (2011) Rotating prism scanning device and method for scanning. Patent No.: WO 2009/155924 A1, 2009

Prospathopoulos J, Politis E, Chaviaropoulos P (2012) Application of a 3D RANS solver on the complex hill of Bolund and assessment of the wind flow predictions. J Wind Eng Ind Aerodyn 107-108:149-159

Rowcroft J, Burton D, Blackburn H, Sheridan J (2014) Surface flow visualisation over forward facing steps with varying yaw angle. J Phys Conf Ser 555. doi:10.1088/1742-6596/555/1/012086

Sacré C (1979) An experimental study of the airflow over a hill in the atmospheric boundary layer. BoundaryLayer Meteorol 17(3):381-401

Silva Lopes A, Palma JMLM, Castro FA (2007) Simulation of the Askervein flow. Part 2: large-eddy simulations. Boundary-Layer Meteorol 125(1):85-108

Sjöholm M, Angelou N, Hansen P, Hansen KH, Mikkelsen T, Haga S, Silgjerd J, Starsmore N (2014) Twodimensional rotorcraft downwash flow field measurements by lidar-based wind scanners with agile beam steering. J Atmos Ocean 31(4):930-937

Smith DA, Harris M, Coffey AS, Mikkelsen T, Jørgensen HE, Mann J, Danielian R (2006) Wind lidar evaluation at the Danish wind test site in Høvsøre. Wind Energy 9(1-2):87-93

Sonnenschein C, Horrigan FA (1971) Signal-to-noise relationships for coaxial systems that heterodyne backscatter from the atmosphere. Appl Opt 10(7):1600

Taylor P, Teunissen H (1985) The Askervein Hill Project: report on the Sept./Oct. 1983 Main Field Experiment. Tech. Rep. Research Report MSRB-84-6. Meteorological Services Research Branch Atmospheric Environment Service, Toronto 
Teunissen HW, Shokr ME, Bowen AJ, Wood CJ, Green DWR (1987) The Askervein Hill Project: wind-tunnel simulations at three length scales. Boundary-Layer Meteorol 40(1-2):1-29. doi:10.1007/BF00140067

Walmsley J, Taylor P (1996) Boundary-layer flow over topography: Impacts of the Askervein study. BoundaryLayer Meteorol 78(3-4):291-320

Yeow T, Cuerva-Tejero A, Perez-Alvarez J (2013) Reproducing the Bolund experiment in wind tunnel. Wind Energy 18(1):153-169. doi:10.1002/we.1688 